\title{
Cortico-Cortical Connections of Primary Sensory Areas and Associated Symptoms in Migraine
}

\author{
(DDuncan J. Hodkinson, ${ }^{1}$ Rosanna Veggeberg, ${ }^{1}$ (1) Aaron Kucyi, ${ }^{2}$ 'Koene R. A. van Dijk, ${ }^{3}$ Sophie L. \\ Wilcox, ${ }^{1}$ Steven J. Scrivani, ${ }^{4}{ }^{-}$Rami Burstein, ${ }^{5}{ }^{-}$Lino Becerra, ${ }^{1}$ and David Borsook ${ }^{1}$
}

DOI:http://dx.doi.org/10.1523/ENEURO.0163-16.2016

${ }^{1}$ Department of Anesthesiology, Perioperative and Pain Medicine, Boston Children's Hospital, Harvard Medical School, Boston, Massachusetts 02115, ${ }^{2}$ Department of Neurology \& Neurological Sciences, Stanford University, Palo Alto, California $94305,{ }^{3}$ Athinoula A. Martinos Center for Biomedical Imaging, Department of Radiology,

Massachusetts General Hospital, Charlestown, Massachusetts 02129, ${ }^{4}$ Department of Oral and Maxillofacial Surgery, Massachusetts General Hospital, Boston, Massachusetts 02115, ${ }^{5}$ Department of Anesthesia and Critical Care, Beth Israel Deaconess Medical Center, Harvard Medical School, Boston, Massachusetts 02115

\begin{abstract}
Migraine is a recurring, episodic neurological disorder characterized by headache, nausea, vomiting, and sensory disturbances. These events are thought to arise from the activation and sensitization of neurons along the trigeminovascular pathway. From animal studies, it is known that thalamocortical projections play an important role in the transmission of nociceptive signals from the meninges to the cortex. However, little is currently known about the potential involvement of cortico-cortical feedback projections from higher-order multisensory areas and/or feedforward projections from principle primary sensory areas or subcortical structures. In a large cohort of human migraine patients $(N=40)$ and matched healthy control subjects $(N=40)$, we used resting-state intrinsic functional connectivity to examine the cortical networks associated with the three main sensory perceptual modalities of vision, audition, and somatosensation. Specifically, we sought to explore the complexity of the sensory networks as they converge and become functionally coupled in multimodal systems. We also compared self-reported retrospective migraine symptoms in the same patients, examining the prevalence of sensory symptoms across the different phases of the migraine cycle. Our results show widespread and persistent disturbances in the perceptions of multiple sensory modalities. Consistent with this observation, we discovered that primary sensory areas maintain local functional connectivity but express impaired long-range connections to higher-order association areas (including regions of the default mode and salience network). We speculate that cortico-cortical interactions are necessary for the integration of information within and across the sensory modalities and, thus, could play an important role in the initiation of migraine and/or the development of its associated symptoms.
\end{abstract}

Key words: connectivity; cortico-cortical; headache; migraine; pain; sensory

\section{Significance Statement}

Migraine is a multifactorial disorder that is associated with abnormalities in sensory processing, including nociceptive and non-nociceptive processing. Here we examine the cortico-cortical circuitry in the migraine brain relating to the principle primary sensory areas (vision, audition, and somatosensation). We also compare self-reported retrospective migraine symptoms in the same patients. Our results identified widespread and persistent disturbances in the perceptions of multiple sensory modalities. Furthermore, we discovered that primary sensory areas maintain local functional connectivity but express impaired long-range connections to higher-order association areas (including regions of the default mode and salience network). These findings provide new insights into the complex symptomatology of migraine and highlight the need to consider network-level cortical processes in the pathophysiology of headache disorders. 


\section{Introduction}

Cutaneous allodynia, photophobia, phonophobia, and osmophobia are clinical symptoms that accompany most migraine attacks. These sensory events may vary in intensity, as the heightened sensitivity in one sensory modality is often associated with heightened sensitivity in the other sensory modalities. The mechanisms proposed to underlie this phenomenon include the activation and sensitization of neurons along the trigeminovascular pathway (Akerman et al., 2011; Bernstein and Burstein, 2012; Pietrobon and Moskowitz, 2013; Burstein et al., 2015). Recent animal studies have shown that dura-sensitive neurons in the thalamus can respond to stimuli from more than one sensory modality (Noseda et al., 2010), and the axonal projections and termination fields of these thalamic trigeminovascular neurons appear to be widespread throughout the neocortex (Noseda et al., 2011). Such extensive inputs to diverse cortical areas may explain some of the common disturbances in neurological functions during migraine (Hodkinson et al., 2015). However, at the early cortical stage, there is the potential involvement of cortico-cortical feedback projections from higher-order multisensory areas (Hackett et al., 1998; Romanski et al., 1999; Lewis and Van Essen, 2000) and/or feedforward projections from principle primary sensory areas or subcortical structures (Falchier et al., 2002; Clavagnier et al., 2004; Cappe and Barone, 2005).

Accumulating evidence suggests that the neural basis of multisensory integration begins in early sensory processing (Ghazanfar and Schroeder, 2006). One hallmark sign of convergence is that responses elicited in primary sensory cortices by corresponding sensory inputs can be modulated by concurrently applied noncorresponding sensory inputs (Ghazanfar et al., 2005; Kayser et al., 2005, 2010; Bizley et al., 2007). Also, the primary sensory cortices do not solely respond to sensory inputs of their own principal modality (Calvert et al., 1997; Meyer et al., 2010, 2011; Liang et al., 2013). This cross-modal interaction between senses (Stein, 1998) is impaired in migraine patients but is not completely disrupted (Brighina et al., 2015). Understanding the interactions that occur when processing multiple external stimuli and activation of the

Received June 15, 2016; accepted November 28, 2016; First published December 21, 2016.

The authors declare no competing financial interests.

Author contributions: D.J.H. and D.B. designed research; D.J.H., R.V., S.J.S., L.B., and D.B. performed research; A.K., K.R.A.v.D., S.L.W., R.B., and L.B. contributed unpublished reagents/analytic tools; D.J.H. analyzed data; D.J.H. wrote the paper.

National Institutes of Health Grants RO1-NS-073977 and K24-NS-064050 funded this study.

Acknowledgments: We thank Dr. Rodrigo Noseda for reviewing the manuscript.

Correspondence should be addressed to Duncan J. Hodkinson, Department of Anesthesiology, Perioperative and Pain Medicine, Boston Children's Hospital, Harvard Medical School, 1 Autumn Street, Boston, MA 02115. E-mail: duncan.hodkinson@childrens.harvard.edu.

DOI:http://dx.doi.org/10.1523/ENEURO.0163-16.2016

Copyright (C) 2016 Hodkinson et al.

This is an open-access article distributed under the terms of the Creative Commons Attribution 4.0 International, which permits unrestricted use, distribution and reproduction in any medium provided that the original work is properly attributed. trigeminal system may help to explain migraine symptoms and mechanisms by which exposure to visual, auditory, and olfactory stimuli can trigger migraine attacks. However, identifying trigger factors or premonitory features that reliably predict headache onset in migraine remains an ongoing clinical challenge (Lipton et al., 2014; Pavlovic et al., 2014).

Intrinsic functional connectivity magnetic resonance imaging (fcMRI) has emerged as a promising new tool for mapping large-scale networks in the resting human brain (Fox and Raichle, 2007). A major application of functional connectivity has been to define distinct regions of cortex (known as cortical hubs) and their corresponding networks (Buckner et al., 2013; Power et al., 2014b). In migraine and other headache disorders, this approach has been used to interrogate specific areas involved in processing pain, affect and emotion, cognition, and pain modulation (Schwedt et al., 2015). However, rather than examining sensory pathways in isolation or in disconnected regions, it has been suggested that perceptual integration is more likely to be achieved via mutual interaction of multiple regions (Ghazanfar and Schroeder, 2006; Harris and Mrsic-Flogel, 2013), thus supporting the hypothesis that the processing of sensory information arises from both local and distant cortico-cortical interactions (Sepulcre et al., 2010, 2012).

In this study, we conducted a systematic assessment of the intrinsic functional connectivity associated with the three main primary sensory areas of vision, audition, and somatosensation. Olfactory and/or chemosensory processes are not considered here because of the lack of a known primary anatomical area. However, it is noteworthy that extensive interactions are also characteristic of these sensory systems (Katz et al., 2001). Specifically, we sought to explore the complexity of the sensory networks as they converge and become functionally coupled in multimodal systems. We also assessed patients' selfreported (retrospective) migraine symptoms, including the prevalence of sensory symptoms at different phases of the attack. We hypothesized that migraineurs would show abnormalities with respect to the networks and regions that are involved in making the complex connections between the primary sensory and higher-order distributed systems of the human brain. Such changes would provide further insights into the complex symptomatology of migraine and address the need to consider "brain-wide" network-level processes in the pathophysiology of headache disorders.

\section{Materials and Methods}

\section{Ethical approval and consent}

The Institutional Review Board at McLean Hospital, Harvard Medical School (Boston, MA) approved the study. All experiments fulfilled the criteria of the Helsinki accord for human research (http://www.wma.net/en/ 30publications/10policies/b3/). Informed written consent was obtained from all participants. 


\section{Inclusion/exclusion criteria}

All participants underwent physical and neurological examinations. Migraine patients had to meet the following criteria to be enrolled into the study: (1) had experienced episodic migraine as classified in the International Classification for Headache Disorders, Second Edition (Headache Classification Subcommittee of the International Headache Society, 2004); (2) had experienced episodic migraine for $\geq 3$ years; and (3) had no migraine $72 \mathrm{~h}$ prior to the study session and no symptoms of migraine development $24 \mathrm{~h}$ after the scan.

A detailed medical history was taken from both patients and the control subjects. Patients were excluded if they had continuous background headache or pain, chronic migraine, or were taking daily medication including prophylactic migraine treatment. Healthy control subjects were excluded if they had any type of migraine or firstdegree relatives with a history of any type of migraine. Females were also excluded if they were pregnant.

\section{Headache characteristics}

Retrospective migraine attack characteristics were collected on study inclusion. A detailed report on the prevalence of sensory symptoms (i.e., photophobia, phonophobia, and osmophobia) was collected at different phases of the patient's typical migraine cycle (i.e., before, during, and after). Patients were also asked to complete the Allodynia Symptom Checklist, assessing the frequency of allodynia symptoms during headache (Jakubowski et al., 2005; Ashkenazi et al., 2007; Lipton et al., 2008). The checklist responses were recorded as categorical (nominal: yes/ no) variables.

\section{Study participants}

Eighty adult right-handed participants were recruited for the study (mean \pm SD age, $32.7 \pm 9$ years; age range, $18-50$ years). The cohort included 40 patients who experienced episodic migraine and 40 individually age-matched ( \pm 1 year) and sex-matched healthy control subjects (10 males/30 females). Migraine patients reported a mean migraine (disease) duration of $15 \pm 9$ years (range, 3-39 years). The attack frequency was recorded as number of episodes per month (6.9 \pm 5 attacks/month). Most patients reported migraine without aura $(N=24)$, but some reported migraine with aura $(N=16)$. Laterality of headache pain was reported as either unilateral ( $N=10$ right-sided, $N=10$ left-sided) or bilateral $(N=20)$. The participants were studied intensively using a range of neuroimaging and behavioral tests, and some of these data have been used to address distinct questions previously (Hodkinson et al., 2016).

\section{MRI acquisition}

Participants were scanned in the supine position on a 3 T Siemens whole-body MRI scanner with a standard 12channel head coil. A high-resolution T1-weighted anatomical scan was acquired using a 3D magnetizationprepared rapid gradient echo sequence (TI, $1100 \mathrm{~ms}$; TR, $2000 \mathrm{~ms}$; TE, $3.5 \mathrm{~ms}$; flip angle, $8^{\circ}$; FOV, $256 \mathrm{~mm}^{2}$; matrix, $256 \times 256$; 224 slices; voxel size, $1 \times 1 \times 1 \mathrm{~mm}$ ). Resting-state fcMRI (rs-fcMRI) data were acquired using a gradient-echo-echoplanar imaging (EPI) sequence [TE,
$30 \mathrm{~ms}$; TR, $2010 \mathrm{~ms}$; flip angle, 90; FOV, $224 \mathrm{~mm}^{2}$; matrix, $64 \times 64$; number slices, 34; slice thickness, $4 \mathrm{~mm}$ (no gap); voxel size, $3.5 \times 3.5 \mathrm{~mm}^{2}$; number of volumes, 300; total scan time, $10 \mathrm{~min}$ and $5 \mathrm{~s}$ ]. Slices were acquired in interleaved ascending order, parallel to the anterior commissure-posterior commissure line. All participants were instructed to stay awake, keep their eyes open, and minimize head movement.

\section{Imaging software}

All imaging data were preprocessed using SPM12 (http://www.fil.ion.ucl.ac.uk/spm) and customized scripts written in MATLAB version R2015a (MathWorks). Visualization of the brain data was performed using CARET software (Computerized Anatomical Reconstruction Toolkit, version 5.65) and the PALS (population average, landmark- and surface-based) surface (Van Essen et al., 2001; Van Essen, 2005). Additional statistical analyses were performed in $\mathrm{R}$ version 3.1.2 (R Foundation for Statistical Computing).

\section{Image preprocessing}

Resting-state fcMRI data were preprocessed in accordance with previously described procedures (Van Dijk et al., 2010, 2012; Power et al., 2012). The steps involved in the pipeline included the following: dropping volumes (the first four volumes of each run were discarded to allow for T1 equilibration effects); slice timing correction (compensation for slice-dependent time shifts were corrected per volume); motion correction (rigid body translation and rotation from each volume to the first volume were used to correct for head motion); spatial normalization [normalization was achieved by computing affine and nonlinear transforms of the mean motion-corrected image to the Montreal Neurological Institute BOLD EPI template]; spatial smoothing (data were resampled to $2 \mathrm{~mm}$ isotropic voxels and spatially smoothed using a $6 \mathrm{~mm}$ full-width at half-maximum Gaussian kernel); motion and physiological regression [reduction of spurious or regionally nonspecific variance was removed by regression of 18 nuisance variables, including six parameters obtained by rigid body head motion correction, with the signal averaged over the whole brain (global signal), the lateral ventricles (CSF), and the white matter, and the first temporal derivative of each regressor also included to account for temporal shifts in the BOLD signal]; and temporal filtering (bandpass filtering was performed with a passband of $0.01-0.08 \mathrm{~Hz}$ ). Filtering was performed by a Butterworth filter with a specified filter order of 4 .

\section{Quality assurance and motion scrubbing}

Particular care was taken to minimize the impact of head motion on the fcMRI correlations. As described previously (Van Dijk et al., 2012), we evaluated in-scanner head motion using the realignment parameters from the SPM Realignment routine. This estimation derives a motion transformation matrix for each time point, including three translations and three rotations. For each individual, the data were passed through a procedure that detects the framewise displacement (FD) of the head from one volume to the next (Power et al., 2012). Frames with a motion level $>0.5 \mathrm{~mm} / \mathrm{TR}$ rotations $>1^{\circ}$ or BOLD signal changes $>2$ SDs were 
A

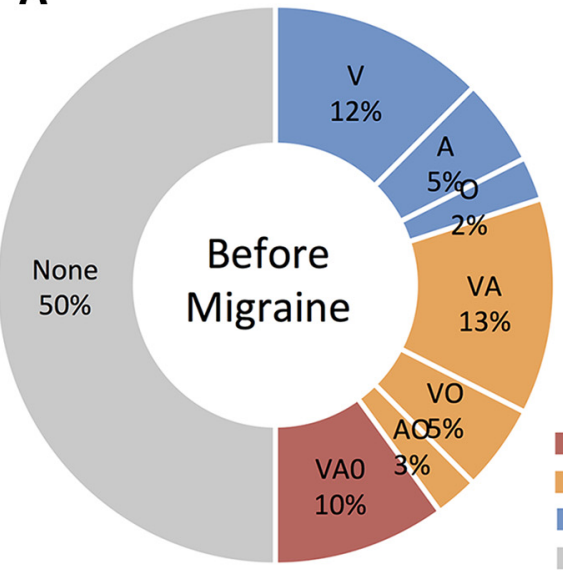

C

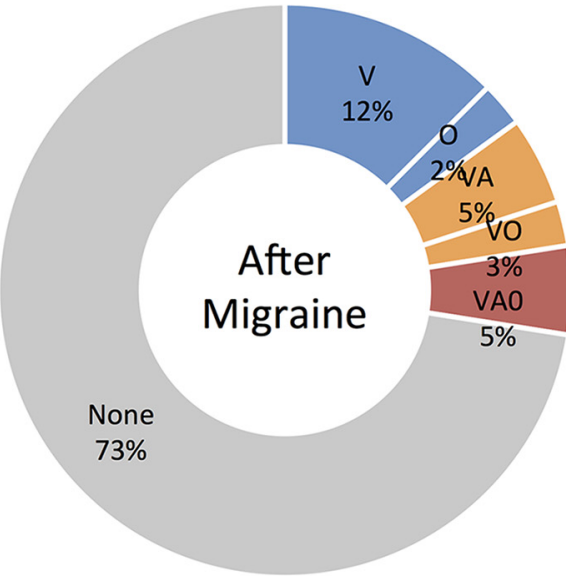

B

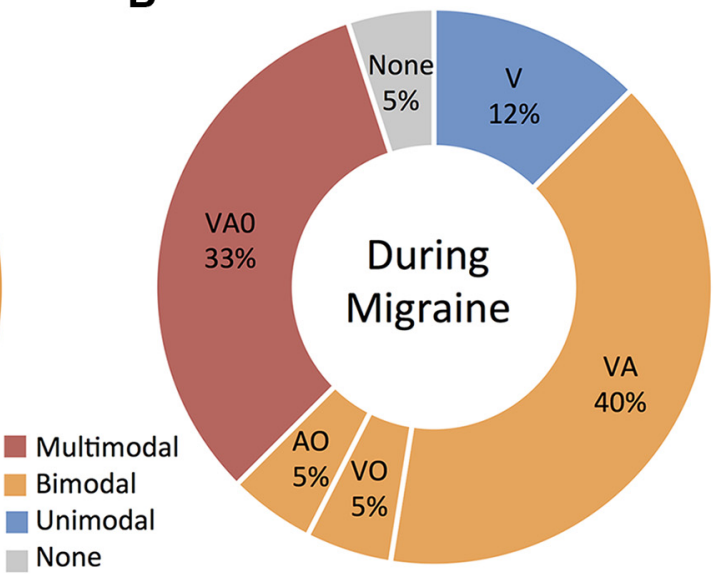

D

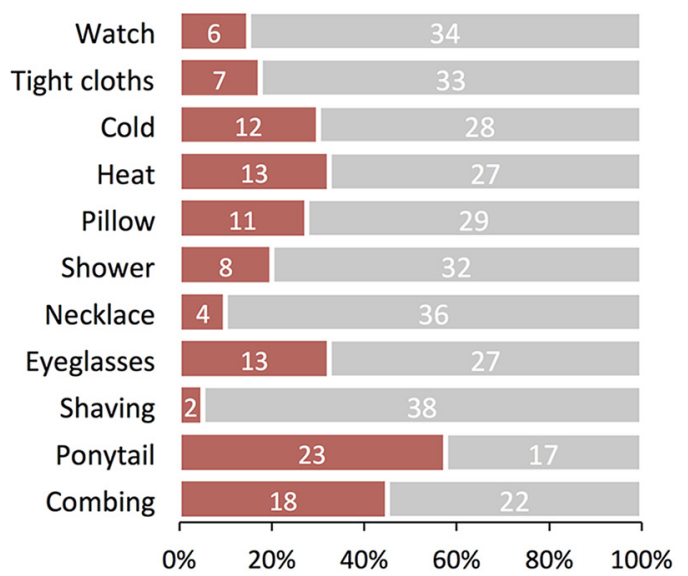

Figure 1. Migraine sensory symptom profile. $\boldsymbol{A}-\boldsymbol{C}$, Total proportion of unimodal, bimodal, and multimodal sensory abnormalities reported before, during, and after migraine attacks (Doughnut plots). V, Photophobia; A, phonophobia; O, osmophobia). D, Total proportion of positive responses to individual questionnaire items of skin hypersensitivity. Histogram shows the percentage of patients that positively reported symptoms, and those that were unaware of any abnormal skin sensitivity (Jakubowski et al., 2005; Ashkenazi et al., 2007; Lipton et al., 2008).

scrubbed from the data. This "scrubbing" procedure used temporal masks to remove motion-contaminated data from regression and correlation calculations by excising unwanted data and concatenating the remaining data. The fraction of frames excluded did not exceed $15 \%$ of the total number of volumes (i.e., $85 \%$ sample retention). We also used measurements of absolute displacement $(A D)$ of the head from the origin position at every time point, including total movement (maximum difference in position in millimeters) and total head rotation (maximum difference in rotation in degrees; Van Dijk et al., 2012). The purpose of these absolute measures is to index head movement, not to precisely model it. As expected, patients with migraine did not have significantly more head motion than healthy control subjects (Table1).

\section{Seed-based analysis}

Six seed regions were chosen to represent networks of the following primary sensory modalities: vision, audition, and somatosensation. The coordinates for these areas were as follows: primary visual cortex (V1): left $(-14,-78$, $8)$; right $(10,-78,8) ; 6 \mathrm{~mm}$ spheres; primary auditory cortex (A1): left $(-54,-14,8)$, right $(58,-14,8), 6 \mathrm{~mm}$ spheres; primary somatosensory cortex (S1): left $(-59$, $-16,41)$; right $(59,-16,41), 4 \mathrm{~mm}$ spheres.

Coordinates for the visual and auditory cortices were taken directly from the literature (Sepulcre et al., 2012). Somatosensory localization of S1 was selected based on the coordinates of an fMRI study involving mechanical stimulation of the forehead representing the ophthalmic trigeminal division, V1 (Moulton et al., 2009). This region was chosen because migraine pain is restricted to the head, often affecting the periorbital area and the eye (Barmettler et al., 2015).

\section{Boundaries of cortical association networks}

Given our hypothesized role of higher-order cortical processes in the pathophysiology of headache disorders, we sought to relate our seed-based analysis with an independent functional atlas derived from a clustering approach 


\section{Visual Cortex functional connectivity}

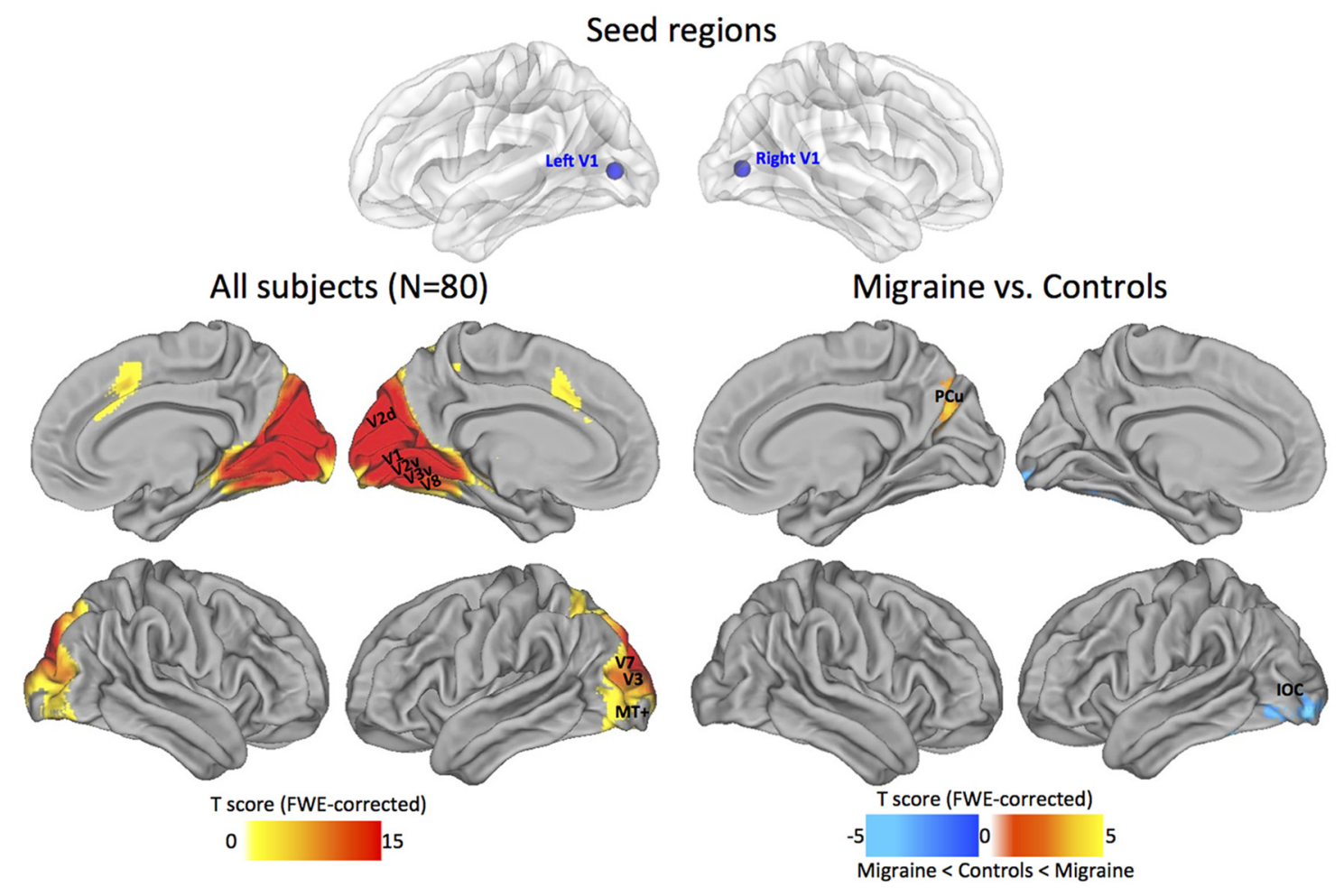

Figure 2. Visual cortex functional connectivity. The statistical maps illustrate the direct connectivity of the visual cortex across all subjects in the sample ( $N=80$; left). Groupwise changes in functional connectivity (migraine vs control subjects) are displayed on the right. All statistical images are displayed with a cluster probability threshold of $p<0.05$, corrected for multiple comparisons (FWE). Seed regions used to generate the contrasts are projected onto glass brains for reference purposes. Data are shown in Caret PALS space, with multiple views of the left/right hemispheres. V1, V2, V3, V7, V8, MT+, Visuotopic areas.

(http://freesurfer.net/fswiki/CorticalParcellation_Yeo2011; Yeo et al., 2011). To quantify changes in specific functional networks, we used the seven-network parcellation scheme provided by Yeo et al. (2011), which is based on data from 1000 healthy adults. The boundaries of these seven networks were projected onto the Ml152 template (see Fig. 7). Groupwise connectivity values were then averaged within each network.

\section{Hierarchical statistical model and contrasts}

Pearson correlation coefficient $(r)$ maps were computed between the mean time course from each of the six seed regions and all other brain voxels. The individual correlation maps were converted to $z$-maps using Fisher's $r$-to- $z$ transformation. Group-level statistical comparisons were computed under the framework of the general linear model using a random-effects flexible factorial ANOVA. In this model, the individual Fisher $z$-transformed correlation maps were the repeated-measures with factors for subject and group. This allowed us to take into account both the differences in variances between the groups and differences (within-subject) across sensory domains of the individual seed maps. This framework has the important advantage of retaining the intrinsic spatial and temporal characteristics of the data without the need for averaging multiple time courses from each seed region or performing dimensionality reduction procedures (Cole et al.,
2010). Contrast specification was designed to examine the increasing complexity of the sensory networks as they converge and become functionally coupled in polymodal systems. Each contrast incorporated the left and right seeds from the primary sensory areas, which were combined as either unimodal (V1, A1, S1), bimodal (V1/A1, V1/S1, A1/S1), or multimodal (V1/A1/S1). Significant clusters were displayed with a probability threshold of $p<$ 0.05 , corrected for multiple comparisons using familywise error (FWE) rate.

\section{Results}

\section{Migraine symptom profile}

Photophobia, phonophobia, and osmophobia

The participants were asked to describe whether they experience any sensory abnormalities before, during, and after migraines (Fig. $1 A-C$ ). A total of $50 \%$ of the patients reported sensory changes before their migraine $(19 \%$ unimodal, $21 \%$ bimodal, $10 \%$ multimodal), whereas $50 \%$ were unaware of any sensory changes. These proportions changed to $95 \%$ with symptoms $(12 \%$ unimodal, $50 \%$ bimodal, $33 \%$ multimodal) and $5 \%$ without symptoms during the migraine attack. Continuing through to the postdrome, $27 \%$ of patients reported at least one type of sensory change after their migraine (14\% unimodal, $8 \%$ bimodal, $5 \%$ multimodal), and $73 \%$ were unaware of any 


\section{Auditory Cortex functional connectivity}
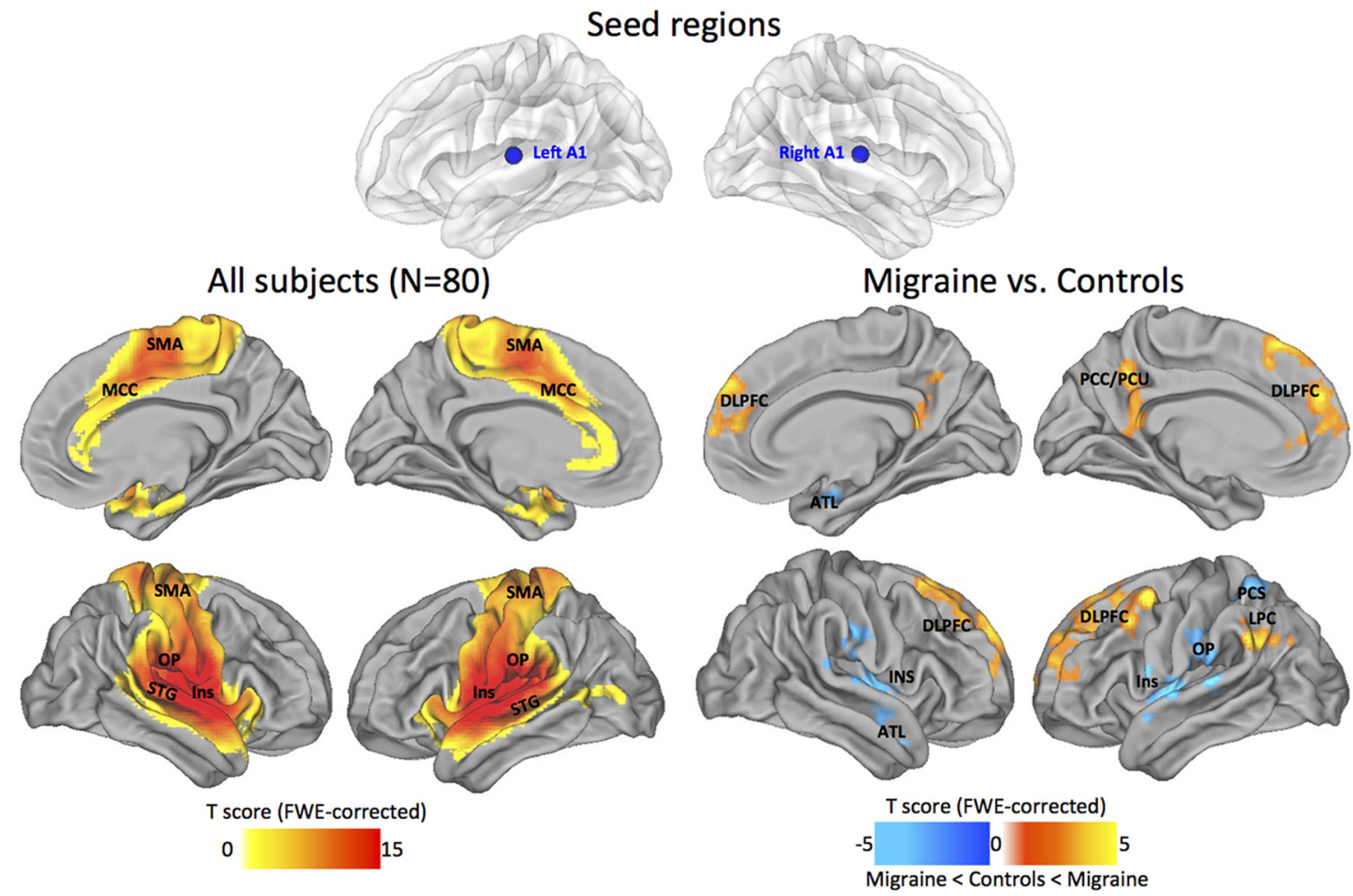

Figure 3. Auditory cortex functional connectivity. The statistical maps illustrate the direct connectivity of the auditory cortex across all subjects in the sample ( $N=80$; left). Groupwise changes in functional connectivity (migraine vs control subjects) are displayed on the right. All statistical images are displayed with a cluster probability threshold of $p<0.05$, corrected for multiple comparisons (FWE). Seed regions used to generate the contrasts are projected onto glass brains for reference purposes. Data are shown in Caret PALS space, with multiple views of the left/right hemispheres.

sensory changes. The proportion of bimodal and multimodal sensory abnormalities was constantly high across all phases of the migraine attack.

\section{Cutaneous allodynia}

Subjects were also asked to fill out a questionnaire to determine whether cutaneous allodynia usually developed during their migraine attack (Fig. 1D). A total of $87 \%$ of the patients reported at least one type of skin hypersensitivity during a migraine attack, and $13 \%$ reported they were unaware of any abnormal skin sensitivity. These proportions changed to $55 \%$ reporting a minimum of three or more symptoms. The total number of positive responses to the individual questions varied greatly. Certain items in the questionnaire were sex specific (e.g., shaving, earrings), some items were not applicable to every patient (e.g., eyeglasses), and not every patient was able to reflect on whether a certain activity was bothersome during migraine (declared unsure).

\section{Unimodal networks \\ Visual cortex}

Across all subjects, from the early visual seeds in V1/ Brodmann area (BA) 17, we found functional connections to the main visuotopic areas: V1, V2, V3, V7, V8, and $\mathrm{MT}+$. Reference boundaries for visuotopic-mapped areas are based primarily on fMRI studies of human retinotopic mapping (Hadjikhani et al., 1998; Van Essen, 2005). In migraine patients compared with control subjects, the visual networks displayed reduced anticorrelation to a small region of the precuneus (PCu) and decreased positive correlations to an area of the inferior occipital cortex (IOC)/middle occipital cortex (Fig. 2).

\section{Auditory cortex}

Across all subjects, the A1 seed locations showed dense connections within local auditory-related regions (including the belt and parabelt), strong connections with operculum (OP), insula (Ins), superiortemporal gyrus (STG), and, to a lesser extent, the sensorimotor area (SMA), and midcingulate cortex (MCC). In the migraine patients compared with control subjects, the auditory networks displayed reduced anticorrelations to regions of the prefrontal cortex [specifically, dorsal lateral prefrontal cortex (DLPFC), PCu, and posterior cingulate cortex (PCC)], and the lateral parietal cortex (LPC). Decreased positive correlations were found to the Ins and OP cortex, posterior central sulcus (PCS), and regions of the anterior temporal lobe (ATL; Fig. 3).

\section{Somatosensory cortex}

Across all subjects, the $\mathrm{S} 1$ periorbital seed locations showed dense connections along the entire somatomotor cortex, with the primary motor and somatosensory cortices interlocked by mutual connections across the central 


\section{Somatosensory Cortex functional connectivity}

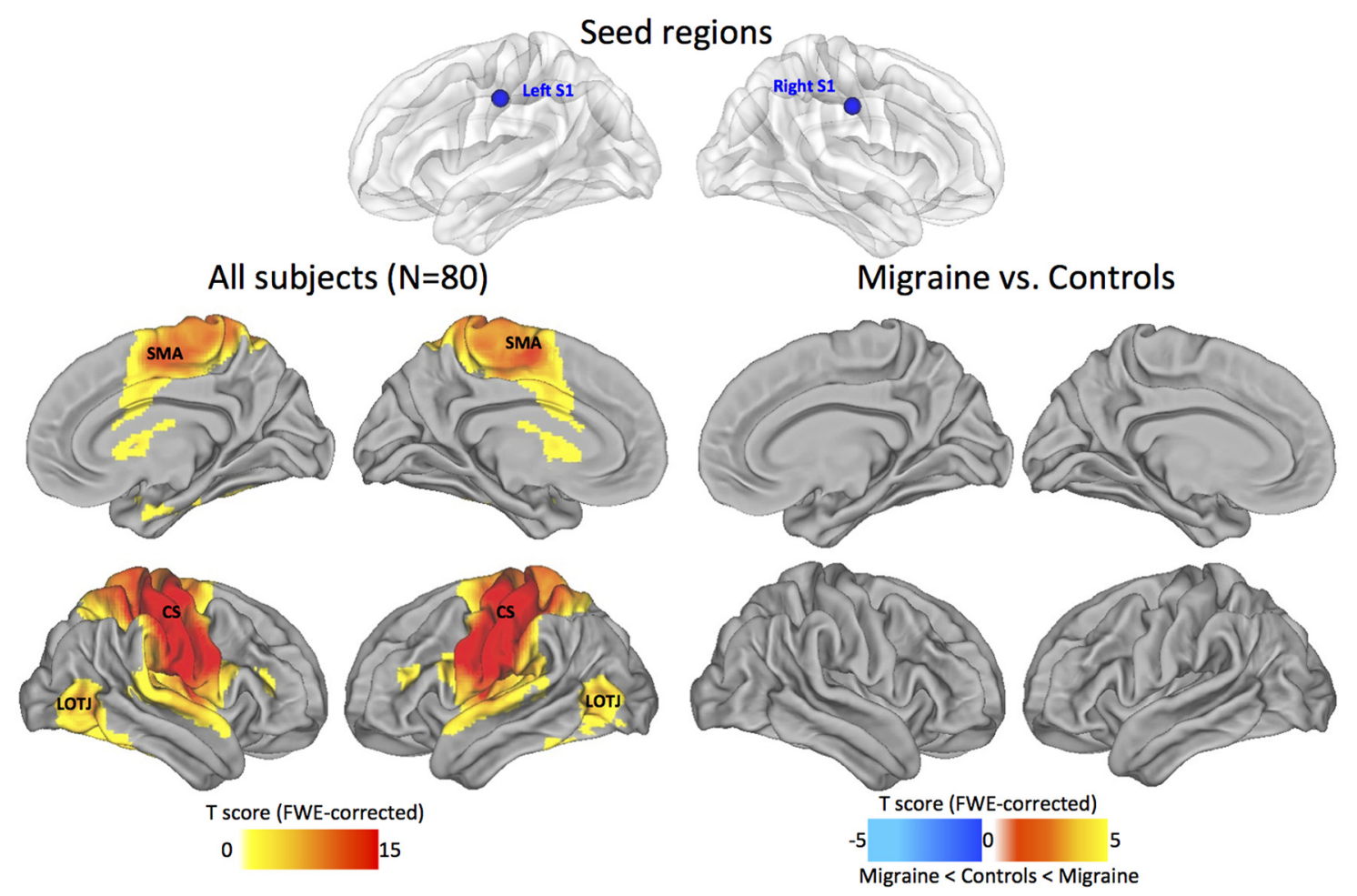

Figure 4. Somatosensory cortex functional connectivity. The statistical maps illustrate the direct connectivity of the somatosensory cortex across all subjects in the sample ( $N=80$; left). Groupwise changes in functional connectivity (migraine vs control subjects) are displayed on the right. All statistical images are displayed with a cluster probability threshold of $p<0.05$, corrected for multiple comparisons (FWE). Seed regions used to generate the contrasts are projected onto glass brains for reference purposes. Data are shown in Caret PALS space, with multiple views of the left/right hemispheres.

sulcus (CS). Weaker connections were present to the lateral occipitotemporal junction (LOTJ). In the migraine patients compared with control subjects, the somatosensory networks displayed no significant changes in positive or negative correlations between the groups (Fig. 4).

\section{Bimodal networks}

Topographically, the functional connectivity patterns for the combined pairs of sensory modalities were remarkably similar to their respective unimodal maps. However, the comparison between migraine patients and control subjects revealed some common features that appeared to converge across all the possible pairs. Specifically, the migraineurs demonstrated reduced anticorrelations with midline medial prefrontal and parietal areas (i.e., PCC/ $\mathrm{PCu}, \mathrm{mPFC} / \mathrm{DLPFC}$ ), and the LPC. Less consistent decreases in positive correlations were observed to the MCC, LOTJ, Ins, and OP cortex (Fig. 5).

\section{Multimodal networks}

Not surprisingly, the functional connectivity pattern from the three sensory modalities was comparable to the unimodal and bimodal maps. However, it is noteworthy that any inconsistencies in the bimodal networks appear to have stabilized in the vicinity of the LOTJ, reflecting a possible common point of convergence among all three sensory modalities (Beauchamp, 2005). Following com- parisons between the migraineurs and control subjects, we revealed a much more defined set of regions than that described in the previous unimodal or bimodal analysis. Specifically, migraineurs demonstrated reduced anticorrelations to distinct cortical regions of the PCC/PCu, mPFC/DLPFC, and LPC, best known as the cortical hubs of the default-mode network (DMN). In the opposite direction, migraineurs showed decreased positive correlations to areas of the MCC and operculoinsular cortex, which have been described as key hubs of the ventral attention/salience network. In addition, the correlation maps showed reduced connectivity to the left LOTJ, left postcentral gyrus (PCG), and ventral/dorsal regions of the ATL (Fig. 6).

\section{Relationship between primary sensory areas and higher-order association networks}

In parallel to the seed-based analyses described above, we separated the cortex into seven large-scale functional networks to examine the integrity of connections between the primary sensory and association areas (Fig. $7 A, B$ ). The amplitude of connectivity values indicates that both groups are normally distributed, and significantly different after paired $t$ tests (sensory-salience: $p=0.0214, t=$ 2.3156; sensory-DMN: $p=0.0015, t=-3.2114$ ). Also, the functional coupling between the correlated and anticorrelated spontaneous activity in DMN and salience net- 


\section{Bimodal functional connectivity}

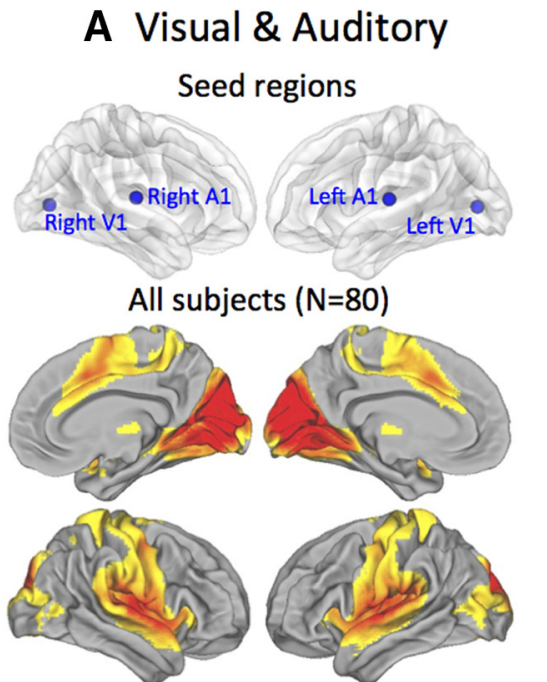

Migraine vs. Controls
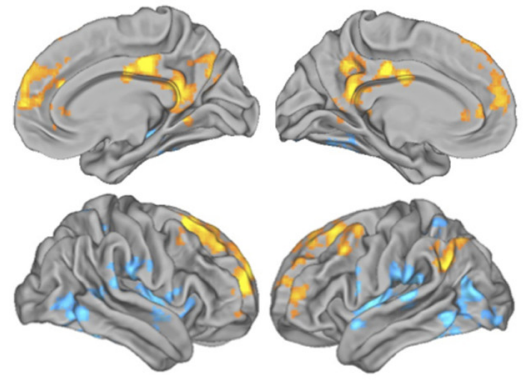

B Visual \& Somatosensory

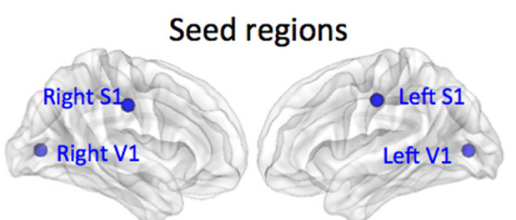

All subjects $(\mathrm{N}=80)$

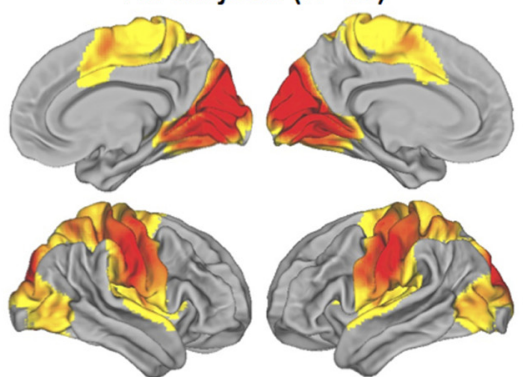

Migraine vs. Controls
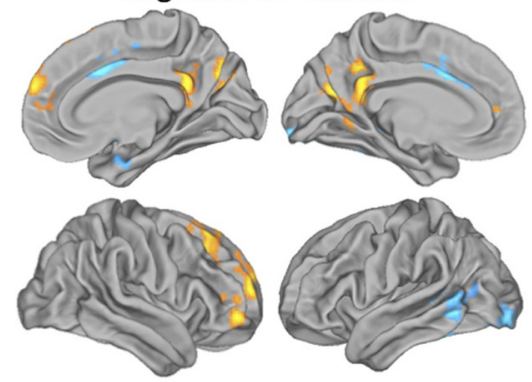

C Auditory \& Somatosensory

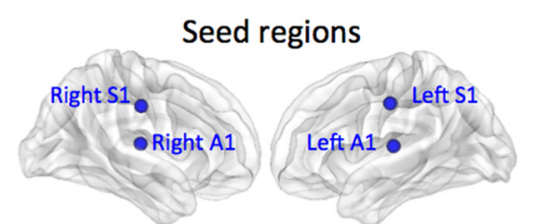

All subjects $(\mathrm{N}=80)$
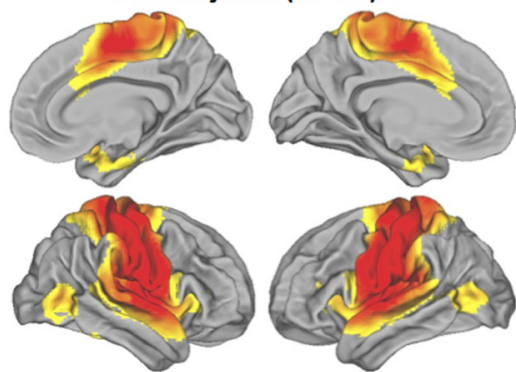

Migraine vs. Controls
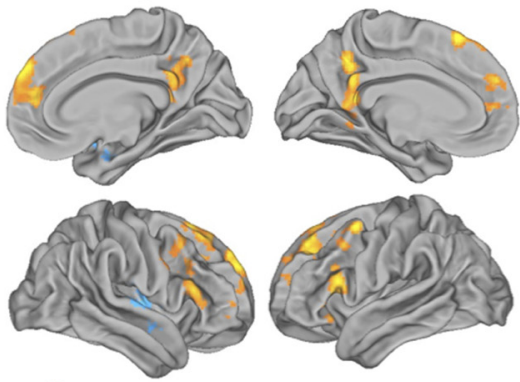

T score (FWE-corrected)

0 15

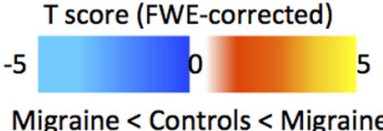

Figure 5. Bimodal functional connectivity. Seed regions used to generate the contrasts are projected onto glass brains for reference purposes (top row). The statistical maps illustrate the connections among visual, auditory, and somatosensory cortices across all subjects in the sample ( $N=80$; middle row). Groupwise changes in functional connectivity (migraine vs control subjects) are displayed on the bottom row. All statistical images are displayed with a cluster probability threshold of $p<0.05$, corrected for multiple comparisons (FWE). Data are shown in Caret PALS space, with multiple views of the left/right hemispheres.

works was impaired in patients with migraine (Pearson's correlation: control subjects: $R^{2}=0.0868, p=3.4 \mathrm{E}-06$; migraine patients: $R^{2}=0.0005, p=0.7305$; Fig. $7 C$ ).

\section{Discussion}

The use of resting-state intrinsic functional connectivity enabled us to examine the cortico-cortical connections in the migraine brain relating to the principle sensory modalities (vision, audition, and somatosensation). These primary systems are recognized as essential cerebral areas for early sensory processing and thus could underlie important pathophysiological processes involved in sensory integration. We discuss the clinical features of migraine and their possible relationship to the disruptions in cortico-cortical interactions.

\section{Disturbances of multiple sensory modalities in migraine}

As expected, the migraine patients reported a high incidence of sensory abnormalities (Fig. 1). Photophobia was the most commonly reported symptom, but the occurrence of phonophobia and/or osmophobia was not uncommon. Of particular interest is the relative proportion of sensory symptoms in the premonitory period continuing through to the postdrome. Nonheadache symptoms are well documented in the premonitory phase of migraine (Giffin et al., 2003), and these findings are consistent with those of other studies indicating that hypersensitivity to sensory stimuli (likely due to central sensitization) is an early phenomenon in the process of a migraine attack (Burstein et al., 2004). Further evidence of central sensitization in the trigeminal-cortical pathway (Burstein et al., 1998) was revealed through the presence of expanding cutaneous allodynia (CA) and hyperalgesia (Burstein et al., 2010). Somatosensory hypersensitivity and the development of CA symptoms occurs in approximately two-thirds of migraineurs during an attack (Ashkenazi et al., 2007; Bigal et al., 2008; Lipton et al., 2008), and approximately the same distribution of CA was reported in our cohort of 


\section{Multimodal functional connectivity (visual, auditory, \& somatosensory)}
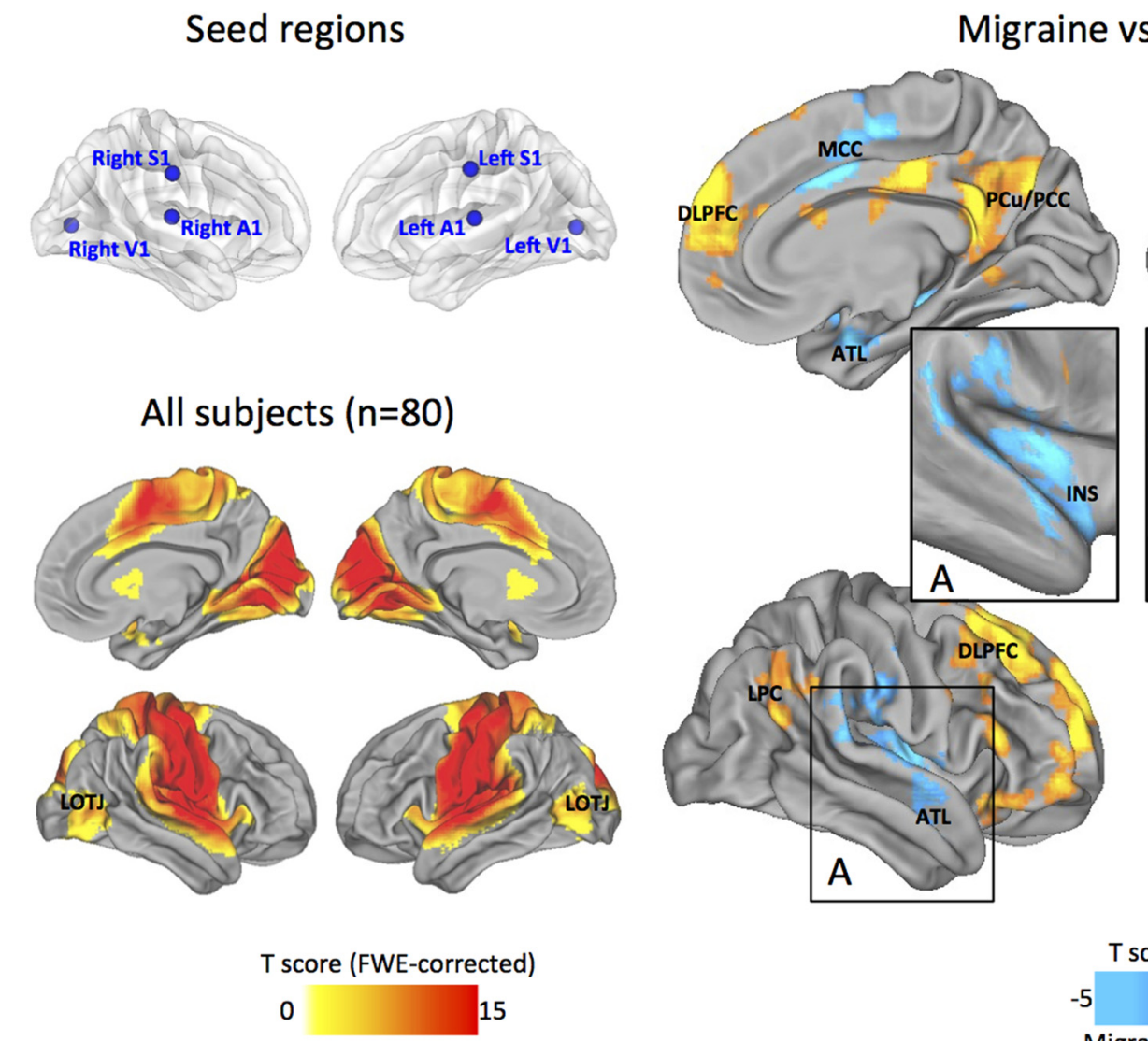

vs. Controls

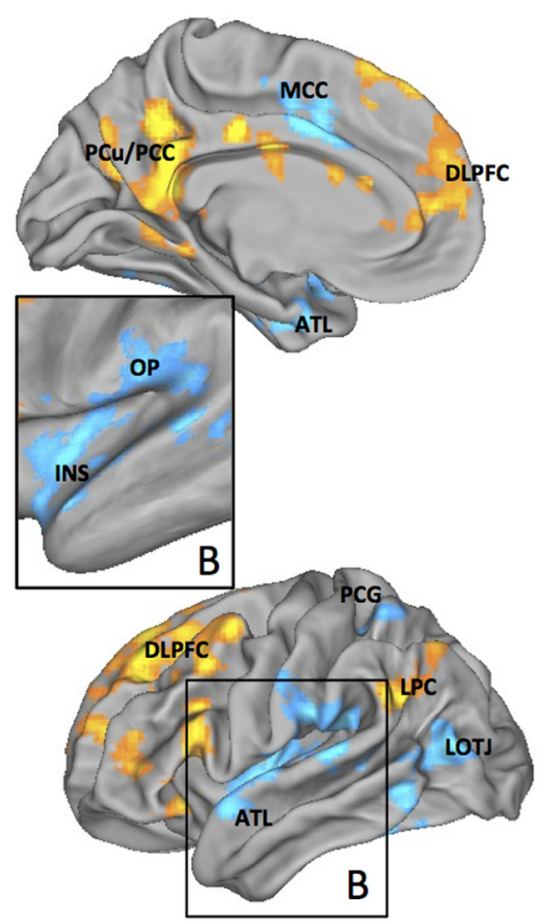

score (FWE-corrected)

15

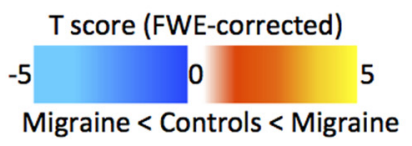

Figure 6. Multimodal functional connectivity. Seed regions used to generate the contrasts are projected onto glass brains for reference purposes (top left). The statistical maps illustrate the connections among all three sensory cortices across all subjects in the sample ( $N=80$; bottom left). Groupwise changes in functional connectivity (migraine vs control subjects) are displayed on the right. To better visualize the INS-OP region we also show the results as inflated projections (inset boxes in $\boldsymbol{A}$ and $\boldsymbol{B}$ ). All statistical images are displayed with a cluster probability threshold of $p<0.05$, corrected for multiple comparisons (FWE). Data are shown in Caret PALS space, with multiple views of the left/right hemispheres.

patients (i.e., $87 \%$ or $55 \%$ reporting one or three or more symptoms, respectively). Together, these clinical features of migraine are consistent with abnormalities in sensory processing, including central sensitization in the trigeminocortical system. The persistent occurrence of photophobia, phonophobia, and/or osmophobia in conjunction with CA (all prominent features of migraine) suggests a common underlying disease pathway involving multisensory integration. This hypothesis is supported by recent evidence showing that cross-modal interaction between senses (Stein, 1998) is impaired in migraine patients (Brighina et al., 2015).

\section{Local connectivity profiles of primary sensory areas}

Early sensory cortical areas are examples of areas with predominantly local hierarchical connections (Felleman and Van Essen, 1991; Sepulcre et al., 2010). In accordance with this view, our maps show consistently high levels of local connectivity across the sensory areas, with the general topography of the seed regions closely tracking the estimated boundaries of the principle cortices (Sepulcre et al., 2010; Yeo et al., 2011). Within the visual cortex, the V1 seed region showed dense local connectivity across the main visuotopic areas $(\mathrm{V} 1, \mathrm{~V} 2, \mathrm{~V} 3, \mathrm{~V} 7, \mathrm{~V} 8$, and MT+; Fig. 2). This observation aligns with both macaque anatomy and estimated human areal boundaries of retinotopically mapped visual areas (Hadjikhani et al., 1998). Regions at or near primary somatosensory and auditory cortices also displayed high levels of local connectivity. In particular, dense local connectivity was observed across BAs 43,42 , and 41 in the auditory cortex, with similar mutual interlocking connections along the entire length of the central sulcus of the somatosensory cortex. Interestingly, we found that the maps possessing multimodal sensory connectivity displayed strong connections with the LOTJ, which might reflect a common point of convergence among all three sensory modalities (Beauchamp, 2005; Fig. 6). Collectively, our analysis 
A
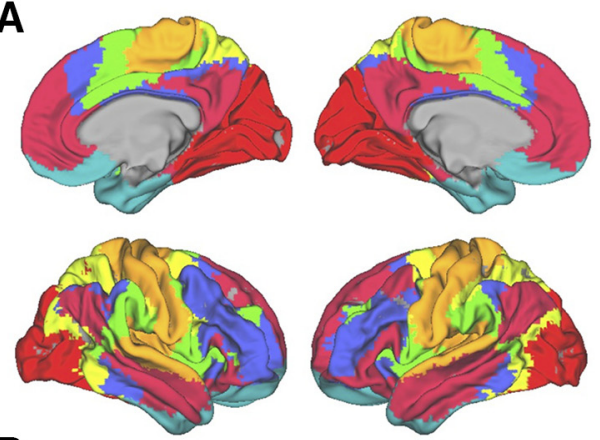

B
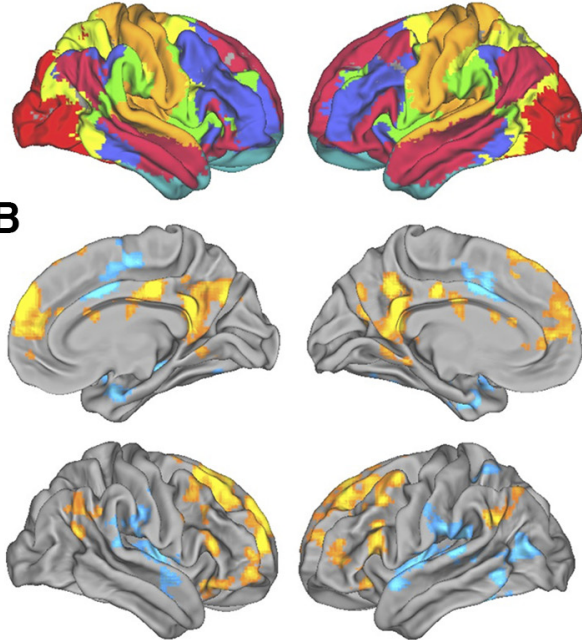
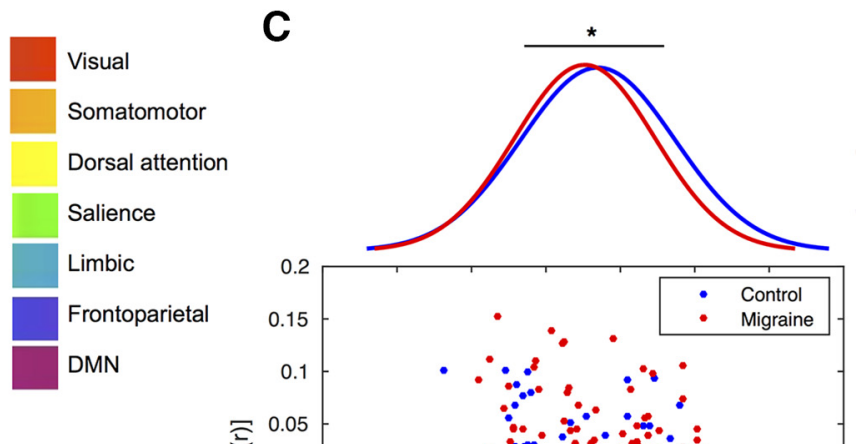
$\mathrm{R} 2=0.0005, \mathrm{P}=0.7305$ Correlations Control: $\mathrm{R} 2=0.0868, \mathrm{P}=3.4 \mathrm{E}-0.6^{\star}$

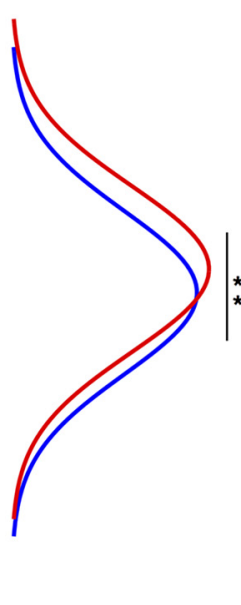

Figure 7. Relationship between primary sensory areas and higher-order associative networks. $\boldsymbol{A}$, Large-scale seven-network parcellation of the human cerebral cortex based on 1000 subjects (top left). $\boldsymbol{B}$, Groupwise changes in functional connectivity between migraine and control groups (bottom left). $\boldsymbol{C}$, Scatter plots and two marginal histograms showing the differences in correlated and anticorrelated spontaneous activity of DMN and salience networks. Both groups are normally distributed and significant after two-tailed $t$ tests. $* p<0.05, * * p<0.005$. Linear trends based on Pearson's linear correlation coefficients $\left(R^{2}\right.$ and $p$ values are displayed in the top-right corner).

shows that local functional connectivity in the primary sensory areas remains intact and appears unaffected by the migraine condition.

\section{Impaired coupling between primary sensory and higher-order associative networks}

In addition to local connectivity profiles, intrinsic functional coupling provides information about long-range between-network interactions. Our results confirm that the changes associated with the sensory systems may affect both correlated and anticorrelated spontaneous activity, causing a shift in the dynamic interplay between two large-scale networks representing opposing components of brain function (Fox et al., 2005; Fig. 7). Considering the relevance of these networks, they have become known as the default mode and ventral attention/salience networks, with multiple hubs capable of long-distance cortico-cortical interactions (Achard et al., 2006; Buckner et al., 2009). While we cannot describe these changes in the context of an activated brain state during migraine, it has been proposed that the salience network represents a basic system through which significant salient events are detected, incorporating afferent information from a variety of somatic and visceral sensory modalities (Craig, 2002, 2003; lannetti and Mouraux, 2010; Critchley and Harrison, 2013). Although no consensus on the function of the default network has been reached, one frequent observation is that this network increases its activity during passive/resting brain states, suggesting a potential role in internal cognitive processes as contrast to stimulus- based perceptions (Andrews-Hanna et al., 2010). Similar features of intrinsic functional connectivity, including deficits relating to the $\mathrm{DMN}$, have been observed in other chronic pain conditions, such as chronic back pain, complex regional pain syndrome, osteoarthritis, and temporomandibular disorder (Loggia et al., 2013; Baliki et al., 2014; Kucyi et al., 2014). Patients with functional pain disorders often complain of generalized sensory hypersensitivity, finding sounds, smells, or even everyday light aversive. Therefore, it is possible that deficits in sensoryprocessing pathways are related to hypersensitivity across the chronic pain population (Pujol et al., 2014).

\section{Limitations, challenges, and future perspectives}

The present work has several potential limitations that are worth considering. First, we were unable to stratify patients according to their clinical symptomatology. This was because the numbers of patients within each of the possible subgroups (i.e., unimodal, bimodal, and multimodal) was much too small; hence, we were unable to assess the direct relationship between functional connectivity and individual differences in the degree or quality of the sensory abnormalities. This interaction may be explored in more detail by future studies to better understand the role of different brain areas in predicting specific phenotypes of migraine (Cucchiara et al., 2015). Second, the impact of head motion can systematically alter correlations in resting state functional connectivity. For example, it has been shown that head movements can produce spurious but structured noise in resting-state scans, thus 
Table 1: Quality assurance and motion scrubbing

\begin{tabular}{llll}
\hline Parameters & Migraine & Control subjects & $p$ value \\
FD & & & \\
Mean movement $(\mathrm{mm})$ & $0.095(0.05)$ & $0.079(0.04)$ & 0.131 \\
Number of movements & $10.85(5.8)$ & $10.75(4.2)$ & 0.931 \\
AD & & & \\
Total movement (mm) & $1.484(1.6)$ & $0.997(0.7)$ & 0.097 \\
Total rotation (degrees) & $0.025(0.02)$ & $0.018(0.01)$ & 0.151
\end{tabular}

Data show the mean $( \pm S D$ ) with associated $p$ value following two-tailed $t$ test. Mean movement, Average change in position between TRs; number of movements, number of motion spikes in the timeseries; total movement, maximum difference in position in millimeters; total rotation, maximum difference in rotation in degrees.

causing distant-dependent changes in signal correlations (Power et al., 2012; Satterthwaite et al., 2012; Van Dijk et al., 2012). To address this problem, several groups have found a benefit of censoring high-motion data (Power et al., 2012; Satterthwaite et al., 2013; Yan et al., 2013a). Accordingly, we used a similar within-subject, censoring-based artifact removal strategy based on volume censoring, which should help to reduce group differences due to motion (Power et al., 2014a). In addition, we performed a systematic assessment of motion-related differences across subjects but found no significant differences between the groups quality assurance parameters (Table 1). Until better motion correction strategies are devised, censoring remains a useful tool for reducing or eliminating motion-related variance in resting-state fMRI data (Power et al., 2015). Third, we acknowledge that global signal regression (GSR) remains a controversial rs-fcMRI data-processing step, particularly for interpreting subsequent anticorrelations (Fox et al., 2009; Murphy et al., 2009; Carbonell et al., 2011; Chai et al., 2012; Keller et al., 2013). The use of GSR in this article was motivated by evidence that it can improve spatial specificity (Fox et al., 2009), correspondence to anatomy (Fox et al., 2009), and agreement with electrophysiology (Keller et al., 2013). Several studies have also shown that regressing the global signal is effective at removing motion artifacts (Satterthwaite et al., 2013; Yan et al., 2013a,b; Power et al., 2014a). However, it is important to note that when rs-fcMRI data are processed with GSR, anticorrelations are effectively mathematically partial correlations controlling for widely shared variance, leading to debate over the appropriate interpretation of observed anticorrelations (Fox et al., 2009; Murphy et al., 2009; Weissenbacher et al., 2009; Carbonell et al., 2011; Chai et al., 2012; Saad et al., 2012; Keller et al., 2013). As the field continues to debate the use of GSR, we remain open as to how best to interpret the changes in anticorrelations.

\section{Conclusion}

In summary, we have shown widespread and persistent disturbances in the perceptions of multiple sensory modalities, which is compatible with the clinical presentation of migraine in the general population. Consistent with these observations, we found that primary sensory areas maintain local functional connections but express impaired long-range connectivity to higher-order association areas (including regions of the default mode and salience network). On the basis of this collective evidence, we propose that cortico-cortical interactions are necessary for the integration of information within and across the sensory modalities and thus could play an important role in the initiation of migraine and/or the development of its associated symptoms.

\section{References}

Achard S, Salvador R, Whitcher B, Suckling J, Bullmore E (2006) A resilient, low-frequency, small-world human brain functional network with highly connected association cortical hubs. J Neurosci 26:63-72. CrossRef

Akerman S, Holland PR, Goadsby PJ (2011) Diencephalic and brainstem mechanisms in migraine. Nat Rev Neurosci 12:570-584. CrossRef Medline

Andrews-Hanna JR, Reidler JS, Sepulcre J, Poulin R, Buckner RL (2010) Functional-anatomic fractionation of the brain's default network. Neuron 65:550-562. CrossRef Medline

Ashkenazi A, Silberstein S, Jakubowski M, Burstein R (2007) Improved identification of allodynic migraine patients using a questionnaire. Cephalalgia 27:325-329. CrossRef Medline

Baliki MN, Mansour AR, Baria AT, Apkarian AV (2014) Functional reorganization of the default mode network across chronic pain conditions. PLoS One 9:e106133. CrossRef Medline

Barmettler G, Brawn J, Maleki N, Scrivani S, Burstein R, Becerra L, Borsook D (2015) A new electronic diary tool for mapping and tracking spatial and temporal head pain patterns in migraine. Cephalalgia 35:417-425. CrossRef Medline

Beauchamp MS (2005) See me, hear me, touch me: multisensory integration in lateral occipital-temporal cortex. Curr Opin Neurobiol 15:145-153. CrossRef Medline

Bernstein C, Burstein R (2012) Sensitization of the trigeminovascular pathway: perspective and implications to migraine pathophysiology. J Clin Neurol 8:89-99. CrossRef Medline

Bigal ME, Ashina S, Burstein R, Reed ML, Buse D, Serrano D, Lipton RB, Group A (2008) Prevalence and characteristics of allodynia in headache sufferers: a population study. Neurology 70:1525-1533. CrossRef Medline

Bizley JK, Nodal FR, Bajo VM, Nelken I, King AJ (2007) Physiological and anatomical evidence for multisensory interactions in auditory cortex. Cereb Cortex 17:2172-2189. CrossRef Medline

Brighina F, Bolognini N, Cosentino G, Maccora S, Paladino P, Baschi R, Vallar G, Fierro B (2015) Visual cortex hyperexcitability in migraine in response to sound-induced flash illusions. Neurology 84:2057-2061. CrossRef Medline

Buckner RL, Krienen FM, Yeo BT (2013) Opportunities and limitations of intrinsic functional connectivity MRI. Nat Neurosci 16:832837. CrossRef Medline

Buckner RL, Sepulcre J, Talukdar T, Krienen FM, Liu H, Hedden T, Andrews-Hanna JR, Sperling RA, Johnson KA (2009) Cortical hubs revealed by intrinsic functional connectivity: mapping, assessment of stability, and relation to Alzheimer's disease. J Neurosci 29: 1860-1873. CrossRef

Burstein R, Yamamura H, Malick A, Strassman AM (1998) Chemical stimulation of the intracranial dura induces enhanced responses to facial stimulation in brain stem trigeminal neurons. J Neurophysiol 79:964-982. Medline

Burstein R, Collins B, Jakubowski M (2004) Defeating migraine pain with triptans: a race against the development of cutaneous allodynia. Ann Neurol 55:19-26. CrossRef Medline

Burstein R, Jakubowski M, Garcia-Nicas E, Kainz V, Bajwa Z, Hargreaves R, Becerra L, Borsook D (2010) Thalamic sensitization transforms localized pain into widespread allodynia. Ann Neurol 68:81-91. CrossRef Medline

Burstein R, Noseda R, Borsook D (2015) Migraine: multiple processes, complex pathophysiology. J Neurosci 35:6619-6629. CrossRef Medline 
Calvert GA, Bullmore ET, Brammer MJ, Campbell R, Williams SC, McGuire PK, Woodruff PW, Iversen SD, David AS (1997) Activation of auditory cortex during silent lipreading. Science 276:593-596. Medline

Cappe C, Barone P (2005) Heteromodal connections supporting multisensory integration at low levels of cortical processing in the monkey. Eur J Neurosci 22:2886-2902. CrossRef Medline

Carbonell F, Bellec P, Shmuel A (2011) Global and system-specific resting-state $\mathrm{fMRI}$ fluctuations are uncorrelated: principal component analysis reveals anti-correlated networks. Brain Connect 1:496-510. CrossRef

Chai XJ, Castañón AN, Ongür D, Whitfield-Gabrieli S (2012) Anticorrelations in resting state networks without global signal regression. Neuroimage 59:1420-1428. CrossRef Medline

Clavagnier S, Falchier A, Kennedy H (2004) Long-distance feedback projections to area $\mathrm{V} 1$ : implications for multisensory integration, spatial awareness, and visual consciousness. Cogn Affect Behav Neurosci 4:117-126. Medline

Cole DM, Smith SM, Beckmann CF (2010) Advances and pitfalls in the analysis and interpretation of resting-state FMRI data. Front Syst Neurosci 4:8. CrossRef Medline

Craig AD (2002) How do you feel? Interoception: the sense of the physiological condition of the body. Nat Rev Neurosci 3:655-666. CrossRef Medline

Craig AD (2003) A new view of pain as a homeostatic emotion. Trends Neurosci 26:303-307. Medline

Critchley HD, Harrison NA (2013) Visceral influences on brain and behavior. Neuron 77:624-638. CrossRef Medline

Cucchiara B, Datta R, Aguirre GK, Idoko KE, Detre J (2015) Measurement of visual sensitivity in migraine: validation of two scales and correlation with visual cortex activation. Cephalalgia 35:585592. CrossRef Medline

Falchier A, Clavagnier S, Barone P, Kennedy H (2002) Anatomical evidence of multimodal integration in primate striate cortex. J Neurosci 22:5749-5759. Medline Medline

Felleman DJ, Van Essen DC (1991) Distributed hierarchical processing in the primate cerebral cortex. Cereb Cortex 1:1-47. Medline

Fox MD, Raichle ME (2007) Spontaneous fluctuations in brain activity observed with functional magnetic resonance imaging. Nat Rev Neurosci 8:700-711. CrossRef Medline

Fox MD, Snyder AZ, Vincent JL, Corbetta M, Van Essen DC, Raichle ME (2005) The human brain is intrinsically organized into dynamic, anticorrelated functional networks. Proc Natl Acad Sci U S A 102:9673-9678. CrossRef Medline

Fox MD, Zhang D, Snyder AZ, Raichle ME (2009) The global signal and observed anticorrelated resting state brain networks. J Neurophysiol 101:3270-3283. CrossRef Medline

Ghazanfar AA, Schroeder CE (2006) Is neocortex essentially multisensory? Trends Cogn Sci 10:278-285. CrossRef Medline

Ghazanfar AA, Maier JX, Hoffman KL, Logothetis NK (2005) Multisensory integration of dynamic faces and voices in rhesus monkey auditory cortex. J Neurosci 25:5004-5012. CrossRef

Giffin NJ, Ruggiero L, Lipton RB, Silberstein SD, Tvedskov JF, Olesen J, Altman J, Goadsby PJ, Macrae A (2003) Premonitory symptoms in migraine: an electronic diary study. Neurology 60: 935-940. Medline

Hackett TA, Stepniewska I, Kaas JH (1998) Subdivisions of auditory cortex and ipsilateral cortical connections of the parabelt auditory cortex in macaque monkeys. J Comp Neurol 394:475-495. Medline

Hadjikhani N, Liu AK, Dale AM, Cavanagh P, Tootell RB (1998) Retinotopy and color sensitivity in human visual cortical area V8. Nat Neurosci 1:235-241. CrossRef Medline

Harris KD, Mrsic-Flogel TD (2013) Cortical connectivity and sensory coding. Nature 503:51-58. CrossRef Medline

Headache Classification Subcommittee of the International Headache Society (2004) The International Classification of Headache Disorders: 2nd edition. Cephalalgia 24 [Suppl1]:9-160.

Hodkinson DJ, Veggeberg R, Wilcox SL, Scrivani S, Burstein R, Becerra L, Borsook D (2015) Primary somatosensory cortices contain altered patterns of regional cerebral blood flow in the interictal phase of migraine. PLoS One 10:e0137971. CrossRef Medline

Hodkinson DJ, Wilcox SL, Veggeberg R, Noseda R, Burstein R, Borsook D, Becerra $L$ (2016) Increased amplitude of thalamocortical low-frequency oscillations in patients with migraine. J Neurosci 36:8026-8036. CrossRef Medline

lannetti GD, Mouraux A (2010) From the neuromatrix to the pain matrix (and back). Exp Brain Res 205:1-12. CrossRef Medline

Jakubowski M, Silberstein S, Ashkenazi A, Burstein R (2005) Can allodynic migraine patients be identified interictally using a questionnaire? Neurology 65:1419-1422. CrossRef Medline

Katz DB, Simon SA, Nicolelis MA (2001) Dynamic and multimodal responses of gustatory cortical neurons in awake rats. $\mathrm{J}$ Neurosci 21:4478-4489. Medline

Kayser C, Petkov Cl, Augath M, Logothetis NK (2005) Integration of touch and sound in auditory cortex. Neuron 48:373-384. CrossRef Medline

Kayser C, Logothetis NK, Panzeri S (2010) Visual enhancement of the information representation in auditory cortex. Curr Biol 20:19-24. CrossRef Medline

Keller CJ, Bickel S, Honey CJ, Groppe DM, Entz L, Craddock RC, Lado FA, Kelly C, Milham M, Mehta AD (2013) Neurophysiological investigation of spontaneous correlated and anticorrelated fluctuations of the BOLD signal. J Neurosci 33:6333-6342. CrossRef

Kucyi A, Moayedi M, Weissman-Fogel I, Goldberg MB, Freeman BV, Tenenbaum HC, Davis KD (2014) Enhanced medial prefrontaldefault mode network functional connectivity in chronic pain and its association with pain rumination. J Neurosci 34:3969-3975. CrossRef

Lewis JW, Van Essen DC (2000) Corticocortical connections of visual, sensorimotor, and multimodal processing areas in the parietal lobe of the macaque monkey. J Comp Neurol 428:112-137. Medline

Liang M, Mouraux A, Hu L, lannetti GD (2013) Primary sensory cortices contain distinguishable spatial patterns of activity for each sense. Nat Commun 4:1979. CrossRef Medline

Lipton RB, Bigal ME, Ashina S, Burstein R, Silberstein S, Reed ML, Serrano D, Stewart WF (2008) Cutaneous allodynia in the migraine population. Ann Neurol 63:148-158. CrossRef

Lipton RB, Pavlovic JM, Haut SR, Grosberg BM, Buse DC (2014) Methodological issues in studying trigger factors and premonitory features of migraine. Headache 54:1661-1669. CrossRef Medline

Loggia ML, Kim J, Gollub RL, Vangel MG, Kirsch I, Kong J, Wasan AD, Napadow V (2013) Default mode network connectivity encodes clinical pain: an arterial spin labeling study. Pain 154:24-33. CrossRef Medline

Meyer K, Kaplan JT, Essex R, Webber C, Damasio H, Damasio A (2010) Predicting visual stimuli on the basis of activity in auditory cortices. Nat Neurosci 13:667-668. CrossRef Medline

Meyer K, Kaplan JT, Essex R, Damasio H, Damasio A (2011) Seeing touch is correlated with content-specific activity in primary somatosensory cortex. Cereb Cortex 21:2113-2121. CrossRef Medline

Moulton EA, Pendse G, Morris S, Aiello-Lammens M, Becerra L, Borsook D (2009) Segmentally arranged somatotopy within the face representation of human primary somatosensory cortex. Hum Brain Mapp 30:757-765. CrossRef Medline

Murphy K, Birn RM, Handwerker DA, Jones TB, Bandettini PA (2009) The impact of global signal regression on resting state correlations: are anti-correlated networks introduced? Neuroimage 44: 893-905. CrossRef Medline

Noseda R, Kainz V, Jakubowski M, Gooley JJ, Saper CB, Digre K, Burstein R (2010) A neural mechanism for exacerbation of headache by light. Nat Neurosci 13:239-245. CrossRef Medline

Noseda R, Jakubowski M, Kainz V, Borsook D, Burstein R (2011) Cortical projections of functionally identified thalamic trigeminovascular neurons: implications for migraine headache and its associated symptoms. J Neurosci 31:14204-14217. CrossRef 
Pavlovic JM, Buse DC, Sollars CM, Haut S, Lipton RB (2014) Trigger factors and premonitory features of migraine attacks: summary of studies. Headache 54:1670-1679. CrossRef Medline

Pietrobon D, Moskowitz MA (2013) Pathophysiology of migraine. Annu Rev Physiol 75:365-391. CrossRef Medline

Power JD, Barnes KA, Snyder AZ, Schlaggar BL, Petersen SE (2012) Spurious but systematic correlations in functional connectivity MRI networks arise from subject motion. Neurolmage 59:2142-2154. CrossRef Medline

Power JD, Mitra A, Laumann TO, Snyder AZ, Schlaggar BL, Petersen SE (2014a) Methods to detect, characterize, and remove motion artifact in resting state fMRI. Neuroimage 84:320-341. CrossRef Medline

Power JD, Schlaggar BL, Petersen SE (2014b) Studying brain organization via spontaneous fMRI signal. Neuron 84:681-696. CrossRef Medline

Power JD, Schlaggar BL, Petersen SE (2015) Recent progress and outstanding issues in motion correction in resting state fMRI. Neuroimage 105:536-551. CrossRef Medline

Pujol J, Macià D, Garcia-Fontanals A, Blanco-Hinojo L, López-Solà M, Garcia-Blanco S, Poca-Dias V, Harrison BJ, ContrerasRodríguez O, Monfort J, Garcia-Fructuoso F, Deus J (2014) The contribution of sensory system functional connectivity reduction to clinical pain in fibromyalgia. Pain 155:1492-1503. CrossRef Medline

Romanski LM, Bates JF, Goldman-Rakic PS (1999) Auditory belt and parabelt projections to the prefrontal cortex in the rhesus monkey. J Comp Neurol 403:141-157. Medline

Saad ZS, Gotts SJ, Murphy K, Chen G, Jo HJ, Martin A, Cox RW (2012) Trouble at rest: how correlation patterns and group differences become distorted after global signal regression. Brain Connect 2:25-32. CrossRef

Satterthwaite TD, Wolf DH, Loughead J, Ruparel K, Elliott MA, Hakonarson H, Gur RC, Gur RE (2012) Impact of in-scanner head motion on multiple measures of functional connectivity: relevance for studies of neurodevelopment in youth. Neuroimage 60:623632. CrossRef Medline

Satterthwaite TD, Elliott MA, Gerraty RT, Ruparel K, Loughead J, Calkins ME, Eickhoff SB, Hakonarson H, Gur RC, Gur RE, Wolf DH (2013) An improved framework for confound regression and filtering for control of motion artifact in the preprocessing of restingstate functional connectivity data. Neuroimage 64:240-256. CrossRef Medline

Schwedt TJ, Chiang CC, Chong CD, Dodick DW (2015) Functional MRI of migraine. Lancet Neurol 14:81-91. CrossRef Medline
Sepulcre J, Liu H, Talukdar T, Martincorena I, Yeo BT, Buckner RL (2010) The organization of local and distant functional connectivity in the human brain. PLoS Comput Biol 6:e1000808. CrossRef Medline

Sepulcre J, Sabuncu MR, Yeo TB, Liu H, Johnson KA (2012) Stepwise connectivity of the modal cortex reveals the multimodal organization of the human brain. J Neurosci 32:10649-10661. CrossRef

Stein BE (1998) Neural mechanisms for synthesizing sensory information and producing adaptive behaviors. Exp Brain Res 123:124135. Medline

Van Dijk KR, Hedden T, Venkataraman A, Evans KC, Lazar SW, Buckner RL (2010) Intrinsic functional connectivity as a tool for human connectomics: theory, properties, and optimization. J Neurophysiol 103:297-321. CrossRef Medline

Van Dijk KR, Sabuncu MR, Buckner RL (2012) The influence of head motion on intrinsic functional connectivity MRI. Neuroimage 59: 431-438. CrossRef Medline

Van Essen DC (2005) A population-average, landmark- and surfacebased (PALS) atlas of human cerebral cortex. Neuroimage 28:635662. CrossRef Medline

Van Essen DC, Drury HA, Dickson J, Harwell J, Hanlon D, Anderson $\mathrm{CH}$ (2001) An integrated software suite for surface-based analyses of cerebral cortex. J Am Med Inform Assoc 8:443-459. Medline

Weissenbacher A, Kasess C, Gerstl F, Lanzenberger R, Moser E, Windischberger C (2009) Correlations and anticorrelations in resting-state functional connectivity MRI: a quantitative comparison of preprocessing strategies. Neuroimage 47:1408-1416. CrossRef Medline

Yan CG, Cheung B, Kelly C, Colcombe S, Craddock RC, Di Martino A, Li Q, Zuo XN, Castellanos FX, Milham MP (2013a) A comprehensive assessment of regional variation in the impact of head micromovements on functional connectomics. Neuroimage 76 : 183-201.

Yan CG, Craddock RC, Zuo XN, Zang YF, Milham MP (2013b) Standardizing the intrinsic brain: towards robust measurement of inter-individual variation in 1000 functional connectomes. Neuroimage 80:246-262.

Yeo BT, Krienen FM, Sepulcre J, Sabuncu MR, Lashkari D, Hollinshead M, Roffman JL, Smoller JW, Zöllei L, Polimeni JR, Fischl B, Liu H, Buckner RL (2011) The organization of the human cerebral cortex estimated by intrinsic functional connectivity. J Neurophysiol 106:1125-1165. CrossRef Medline 